
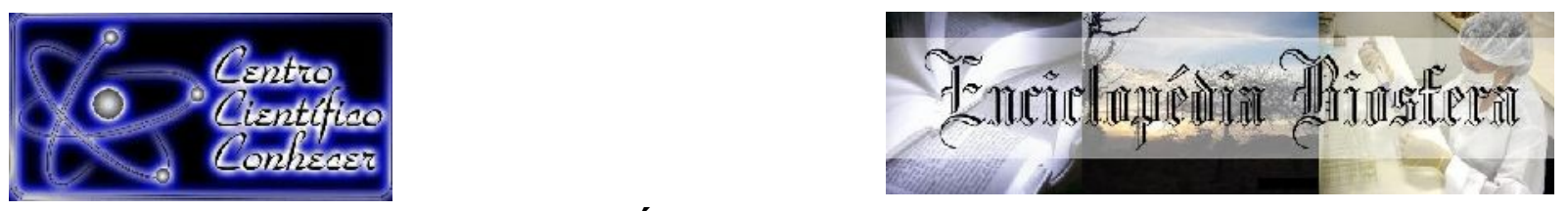

\title{
QUALIDADE MICROBIOLÓGICA DE BIOPRODUTOS COMERCIAIS MULTIPLICADOS ON FARM NO VALE DO SÃO FRANCISCO: DADOS PRELIMINARES
}

\author{
Adailson Feitoza de Jesus Santos ${ }^{1^{*}}$, Sophia Santos Eleftherios Dinnas ${ }^{2}$, Adriane Freire \\ Araújo Feitoza \\ ${ }^{1}$ Prof. Dr. Universidade do Estado da Bahia - UNEB - Departamento de Tecnologia e \\ Ciências Sociais - Campus III - Juazeiro/BA \\ ${ }^{2}$ Discente do Curso de Engenharia de Bioprocessos e Biotecnologia da Universidade do \\ Estado da Bahia - UNEB - Departamento de Tecnologia e Ciências Sociais - Campus \\ III - Juazeiro/BA - \\ *afsantos@uneb.br
}

Recebido em: 15/11/2020 - Aprovado em: 15/12/2020 - Publicado em: 30/12/2020

DOI: 10.18677/EnciBio_2020D33

\begin{abstract}
RESUMO
O uso de produtos de origem microbiana, bactérias e fungos, para a agricultura tem crescido exponencialmente no mundo, e no Brasil este crescimento é significativo. Nos últimos anos várias empresas se instalaram no país e passaram a desenvolver diversos produtos neste segmento. $O$ produtor, tem a possibilidade de multiplicar bactérias nas próprias fazendas em um processo chamado "on farm", uma forma caseira de multiplicar bactérias. $O$ objetivo deste trabalho foi avaliar a qualidade microbiológica dos multiplicados produzidos on farm no Vale do São Francisco. Para isto 12 amostras de multiplicados de diversas bactérias foram coletadas em cinco propriedades diferentes. Foram analisados o pH, quantidade total de bactérias heterotróficas, coliformes totais, coliformes termotolerantes, análise macro e microscópica e presença de Salmonella sp. As análises mostraram contaminação em 100\% das amostras. Nenhuma das amostras identificadas como contendo Chromobacterium subtsugae e Saccharopolyspora spinosa continham a bactéria alvo da multiplicação. Cerca de $84 \%$ das amostras apresentaram quantificações elevadas de coliformes totais e $75 \%$ foram positivas para coliformes termotolerantes. Empregando o meio de cultura seletivo Ágar Salmonella-Shigella, 75\% das amostras tiveram presença provável de Salmonella sp. O sistema de multiplicação on farm nas propriedades analisadas apresentam problemas quanto a qualidade microbiológica. Podem representar risco potencial para a saúde dos manipuladores, bem como para os consumidores finais, ainda desencadear baixa eficiência agronômica das bactérias utilizadas como fonte de inóculo.
\end{abstract}

PALAVRAS-CHAVE: bioinsumos; contaminação; controle biológico 


\title{
MICROBIOLOGICAL QUALITY OF BIOPRODUCTS MULTIPLIED ON FARM IN THE SÃO FRANCISCO VALLEY: PRELIMINARY DATA
}

\begin{abstract}
The use of microbial products, bacteria and fungi, in agriculture has increased exponentially around the world, with a significant rise in Brazil. In recent years, several companies were founded in our country and started to develop numerous products in this sector. The producer, has the opportunity to multiply bacteria on the farms in a process called "on farm", a homemade way of multiplying bacteria. The goal of this work was to evaluate the microbiological quality of the products generated on farms in the São Francisco Valley. For this, 12 samples of products of different bacteria were collected in five different properties. The $\mathrm{pH}$, total amount of heterotrophic bacteria, total coliforms, thermotolerant coliforms, macro and microscopic analysis and the presence of Salmonella spp. were tested. The analyzes showed contamination in $100 \%$ of the samples. None of the samples identified as containing Chromobacterium subtsugae and Saccharopolyspora spinosa contained the target bacteria for multiplication. About $84 \%$ of the samples showed high amounts of total coliforms and $75 \%$ were positive for thermotolerant coliforms. Using the Salmonella-Shigella Agar selective culture medium, $75 \%$ of the samples were likely to have Salmonella sp. The on farm multiplication system exhibited problems in terms of microbiological quality. Consequently, it can represent a potential risk to the health of the handlers, as well as to the final consumers, triggering low agronomic efficiency of the bacteria used as a source of inoculum.
\end{abstract}

KEYWORDS: Bioinsumption; contamination; biological control

\section{INTRODUÇÃO}

O uso de produtos biológicos na agricultura tem apresentado grande crescimento nos últimos anos. Este fato se deve principalmente as pesquisas que demonstram os benefícios econômicos destes produtos e a credibilidade alcançada nos sistemas de manejo integrado das culturas. Produtos biológicos são aqueles que contém microorganismos ou derivados microbianos como agentes ativos, com potencial benéfico e de ocorrência natural (ADESEMOY, 2017). Os dois principais grupos de biológicos de interesse agrícola são os bioestimulantes e os biopesticidas (ADESEMOY, 2017). Bactérias e fungos compreendem o maior percentual de produtos biológicos para a agricultura.

Este mercado aquecido tem gerado grande desenvolvimento de empresas no segmento de produção de produtos biológicos. Dados oficiais do Ministério da Agricultura, Pecuária e Abastecimento (MAPA) mostram que de 2006 a 2018 houve um salto de 1 para 79 empresas neste segmento no Brasil. A mesma tendência é encontrada para o registro de produtos biológicos (BORSARI; CLAUDINO, 2018). A expectativa é que este cenário seja ainda mais favorecido com o Decreto (10.375 de 26 de maio de 2020) que institui o Programa Nacional de Bioinsumos que visa, entre outros aspectos, estimular o desenvolvimento do setor no País com foco nas pequenas e médias biofábricas.

Durante 0 processo industrial para produção de produtos a base de microrganismos são seguidos rigorosos procedimentos para garantir a qualidade final 
do produto. Sendo inclusive necessário, durante o registro de qualquer produto que tenha como base agentes biológicos para o controle de pragas, ser informado sobre a possível presença de toxinas microbianas e outros metabólitos, estirpes mutantes, substâncias alergênicas etc. (BRASIL, 2002). É exigido pela Agência Nacional de Vigilância Sanitária (ANVISA), o estudo detalhado sobre os resíduos quando o produto for indicado para uso em culturas para fins de alimentação humana ou animal, ou ainda, quando o uso do produto puder resultar na presença de resíduos em alimento humano ou animal (BRASIL, 2012). Ainda há, a exigência do Instituto Brasileiro do Meio Ambiente e Recursos Naturais Renováveis (IBAMA) para que sejam realizadas avaliações de danos sobre organismos não-alvo e comportamento ambiental do agente microbiológico de controle (BRASIL, 2012). Os trâmites burocráticos devem ser seguidos para garantia de um produto com $100 \%$ de confiabilidade.

Em julho de 2009, foi sancionado o decreto de $n^{\circ}-6.913$, onde no seu artigo $1^{\circ} \mathrm{e}$ $\S 8^{\circ}$ fica determinado que "ficam isentos de registro os produtos fitossanitários com uso aprovado para a agricultura orgânica produzidos exclusivamente para uso próprio." A partir deste decreto, houve um crescimento exponencial da produção de produtos de origem microbiológica nas próprias fazendas, o qual foi denominado de multiplicação on farm. Nesse sistema, são utilizados, na grande maioria, caixas d'água, onde o produtor adiciona um meio de cultura, água, antiespumante, açúcar cristal e o inóculo microbiano. Esta última proveniente, na maior parte dos casos, de um produto comercial com registro e em outros casos de produtos que não possuem registro, nem mesmo apresentam no rótulo, a identificação do provável agente microbiano. Para a multiplicação, injeta-se ar na solução através de um sistema de tubulação para garantir a aeração do sistema. E via de regra, após 48 horas de funcionamento do sistema, o multiplicado está pronto para uso.

Um ponto problemático, porém, não é o único, é o fato de o sistema não ser estéril, ou seja, ao adicionar a fonte de microrganismo alvo, haverá a presença de diversos outros provenientes da água, do ar, do açúcar, do antiespumante e do próprio meio de cultura. A esterilização é um processo, físico ou químico, que elimina todas as formas de vida (vegetativas e esporuladas). Reatores bioquímicos e tubulações são, geralmente, esterilizados pela aplicação de calor úmido (vapor saturado) (SCHMIDELL et al., 2001).

A presença de uma única célula de um microrganismo contaminante pode ser suficiente para garantir sua multiplicação em taxas, algumas vezes, maior que a do microrganismo alvo, colocando a perder todo um lote do produto (SCHMIDELL et al., 2001), gerando um produto sem efeito agronômico e com contaminantes que podem representar riscos para humanos. Assim, o objetivo do presente trabalho foi avaliar a qualidade microbiológica de diferentes multiplicados on farm no vale do São Francisco.

\section{MATERIAL E MÉTODOS}

No presente estudo, foram coletadas amostras de multiplicados bacterianos em cinco fazendas diferentes. As amostras foram submetidas a testes de qualidade microbiológica para contagem de heterotróficos totais, de coliformes totais e termotolerantes e presença/ausência de Salmonella-Shigella sp..

Foram coletados $250 \mathrm{~mL}$ de multiplicados provenientes de oito diferentes produtos contendo diferentes espécies de bactérias comercializadas no Vale do São 
Francisco totalizando 12 amostras (Quadro 1). As amostras foram coletadas em recipientes estéreis e transportadas até o laboratório em caixas térmicas para 0 imediato processamento.

Antes das análises microbiológicas, foi determinado o $\mathrm{pH}$ de cada amostra. Para determinação da quantificação de bactérias totais presentes no multiplicado, foram realizadas diluições seriadas $\left(10^{-1}\right.$ a $\left.10^{-9}\right)$ em solução salina $0,85 \%$. Cem microlitros de cada diluição foi plaqueada (spread plate) em triplicada em placas de Petri, contendo meio de cultura Agar Triptona de Soja (TSA). As placas foram incubadas a $28 \pm 2{ }^{\circ} \mathrm{C}$ por 24 horas a 144 horas. Foi realizada a quantificação e os resultados expressos em Unidades Formadoras de Colônias (UFC). Colônias morfologicamente distintas de cada amostra foram repicadas em novas placas contendo o mesmo meio e incubadas sob as mesmas condições. Para as colônias isoladas e purificadas foi realizada a coloração de Gram e as colônias foram preservadas em glicerol 50\% para estudos posteriores.

Para a quantificação de Coliformes Totais e Termotolerantes foi utilizada a metodologia recomendada pela U.S. Food and Drug Administration (FDA, 2020), onde emprega-se a técnica do número mais provável (NMP). De cada amostra, diluições seriadas foram realizadas $(0,1 ; 0,01$ e 0,001$)$ em $9 \mathrm{mLde}$ água peptonada $(0,1 \%)$. Cada diluição foi inoculada em série de três tubos contendo Caldo Lauril Sulfato Triptose (LST) com tubos de Durhan invertidos. As diluições foram incubadas a $35 \pm 0,5^{\circ} \mathrm{C}$. Os tubos foram examinados após $24 \pm 2 \mathrm{~h}$ para a turvação e produção de gás. Os tubos negativos foram mantidos incubados por mais $24 \mathrm{~h}$ e examinados novamente. Para cada amostra positiva, uma alíquota, com auxílio de alça de platina, foi inoculada em tubos contendo meio Caldo Bile Verde Brilhante 2\% (VLB) e meio Caldo Escherichia coli (EC), ambos com tubos de Durhan invertidos. Os tubos foram incubados a $35 \pm 0,5$ ${ }^{\circ} \mathrm{C}$ e $44.5 \pm 0,5^{\circ} \mathrm{C}$, respectivamente. Os tubos foram examinados após $24 \pm 2 \mathrm{~h}$ para a turvação e produção de gás. Os tubos negativos foram mantidos incubados por mais 24 $\mathrm{h}$ e examinados novamente. Os resultados foram analisados em tabela de número mais provável (NMP) (SILVA et al., 2010).

Para a detecção da presença de Salmonella sp. foi utilizado o meio de cultura seletivo Agar Salmonella-Shigella (SS). Com auxílio de alça de platina, amostras dos multiplicados foram estriadas em meio SS. Em seguida foram incubadas a $35 \pm 2{ }^{\circ} \mathrm{C}$. A interpretação dos resultados é realizada de acordo com a coloração desenvolvida pelas colônias. Colônias incolores com centro negro - suspeita de Salmonella spp., colônia incolor - suspeita de Shigella spp. e colônias cor de rosa ou vermelho - suspeita de Escherichia coli ou Klebsiella spp. (BRASIL 2011).

\section{RESULTADOS E DISCUSSÃO}

A Figura 1 apresenta as instalações onde os multiplicados testados foram produzidos. É importante verificar a diferença entre os ambientes. Nas Figuras 1C e 1D, pode-se verificar que há um menor cuidado em relação ao ambiente onde as caixas estão dispostas, aliada ainda, a falta de tampas nos sistemas de multiplicação. Embora o ambiente tenha sido variável, o sistema de multiplicação adotado nas 5 fazendas é basicamente o mesmo. Contando com uma estrutura de caixa d'água para a multiplicação, a qual está acoplada a dois sistemas de tubulação, um para a injeção de água e retirada do multiplicado e um outro para injeção de ar para a areação durante a multiplicação. Durante as coletas foi verificado que para as 12 amostras são utilizados 
apenas 2 tipos de meios de cultura diferentes, comercializados na região. Como forma de preservar as marcas, os meios foram identificados como M1 e M2 (Quadro 1). Os meios de cultura não apresentam no rótulo a composição nutricional básica, bem como informações sobre o processo de esterilização industrial. A composição nutricional, principalmente fontes de carbono e nitrogênio, são fundamentais, pois os nutrientes absorvidos e transformados pelos microrganismos serão a base para síntese dos metabólitos de interesse (ZHANG et al., 2020). Em algumas fazendas, os meios são armazenados no mesmo local onde ocorre a multiplicação.

FIGURA 1. Instalações onde o processo de multiplicação on farm é realizado. Cada letra representa uma propriedade diferente.

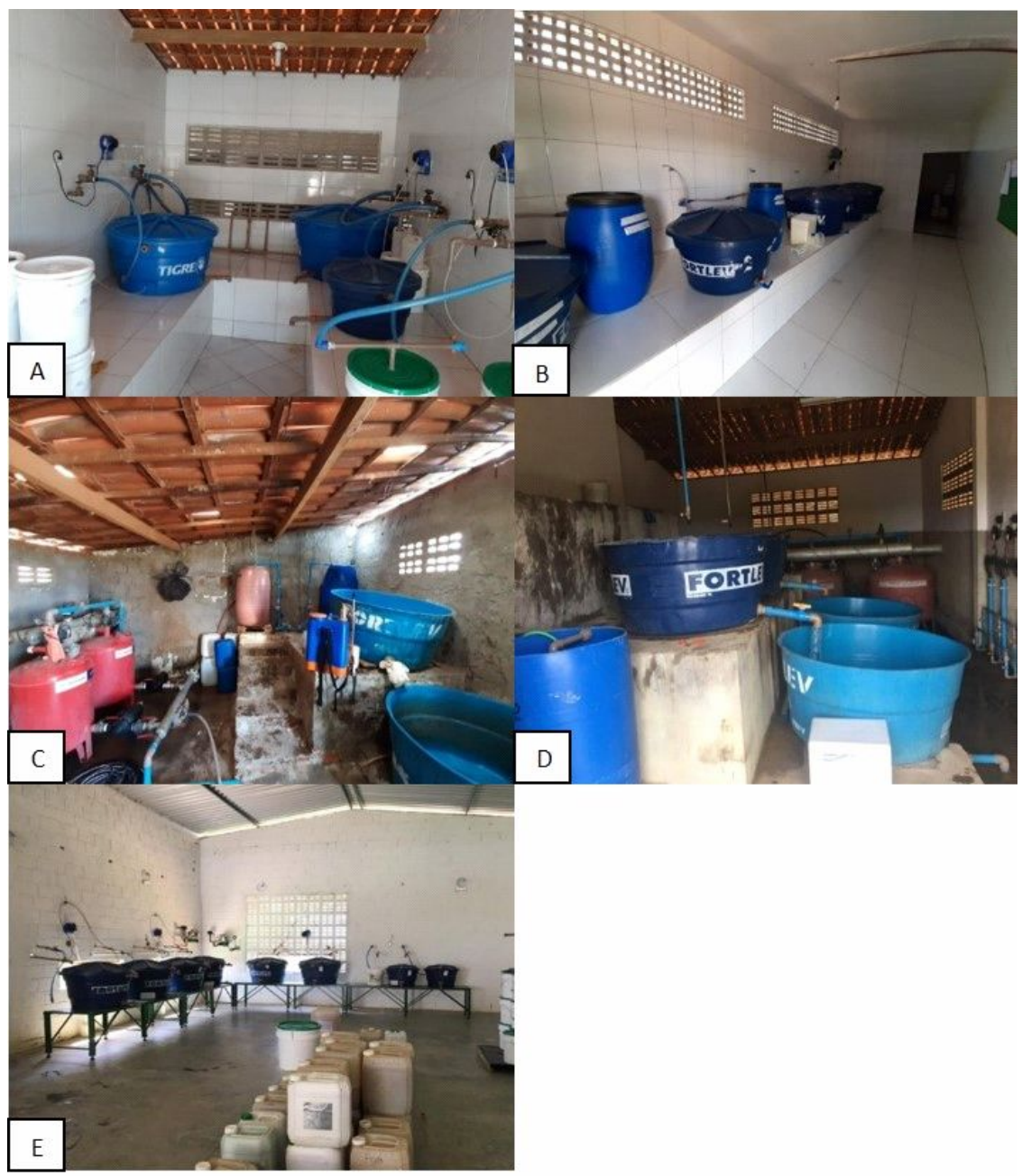

Fonte: os autores (2020)

Independente das condições das instalações é fundamental que sejam consideradas que todos os sistemas utilizados são passíveis de contaminação, a saber: 
o ar, a água, o meio de cultura, o antiespumante, o açúcar e o processo em si. Quando consideradas instalações adequadas para processos fermentativos industriais de microrganismos, um dos aspectos mais importantes é a redução da possibilidade de contaminantes no produto final. O que é alcançado a partir da utilização de reatores vedados, com entrada de ar, água e nutrientes esterilizados, sendo possível controlar, além destes parâmetros, $0 \mathrm{pH}$, a temperatura, a taxa de oxigênio dissolvido, entre outros (JAGANI et al., 2010). Garantindo desta forma a multiplicação dos microrganismos de interesse sem a presença de contaminantes e/ou metabólitos indesejados.

QUADRO 1. Caracterização das amostras analisadas, codificação das cinco propriedades e dos dois meios de cultura utilizados para multiplicação on farm.

\begin{tabular}{|l|c|c|c|}
\hline Amostras & Propriedade & $\begin{array}{c}\text { Meio de } \\
\text { Cultura }\end{array}$ & $\mathrm{pH}$ \\
\hline A1 - E (Bacillus amyloliquefaciens D-747) & FF & M1 & 4,5 \\
\hline A2 - G (Chromobacterium subtsugae - PRAA4-1T) & FF & M1 & 5,0 \\
\hline A3 - A (Azospirillum brasilense) & FF & M1 & 4,0 \\
\hline A4 - P (Saccharopolyspora spinosa) & FA & M2 & 4,0 \\
\hline A5-B (Bacillus thuringiensis var. kurstaki HD-1) & FA & M2 & 4,3 \\
\hline A6- CS1 (Saccharopolyspora spinosa) & FP & M2 & 8,5 \\
\hline A7- CC1 (Chromobacterium sp.) & FP & M2 & 4,0 \\
\hline A8-S1 (Bacillus subtilis QST 713) & FP & M2 & 4,0 \\
\hline A9-S2 (Bacillus subtilis QST 713) & FJ & M1 & 5,0 \\
\hline A10-CS2 (Saccharopolyspora spinosa) & FI & M1 & 3,0 \\
\hline A11-CC2 (Chromobacterium sp.) & FI & M1 & 4,0 \\
\hline A12-S3 (Bacillus subtilis QST 713) & FI & M1 & 4,0 \\
\hline
\end{tabular}

Os multiplicados apresentaram "aparência" variável tanto entre as diferentes fontes bacterianas como para o mesmo grupo de bactérias (Figura 2). A aparência do multiplicado pode ser influenciada pelo meio de cultura e pelo metabolismo dos microrganismos fermentados. Porém, empregando-se o mesmo meio de cultura, a mesma fonte bacteriana e o mesmo sistema de multiplicação, é esperado que as características do multiplicado sejam semelhantes.

FIGURA 2. Característica dos multiplicados bacterianos on farm após 48 horas de multiplicação.

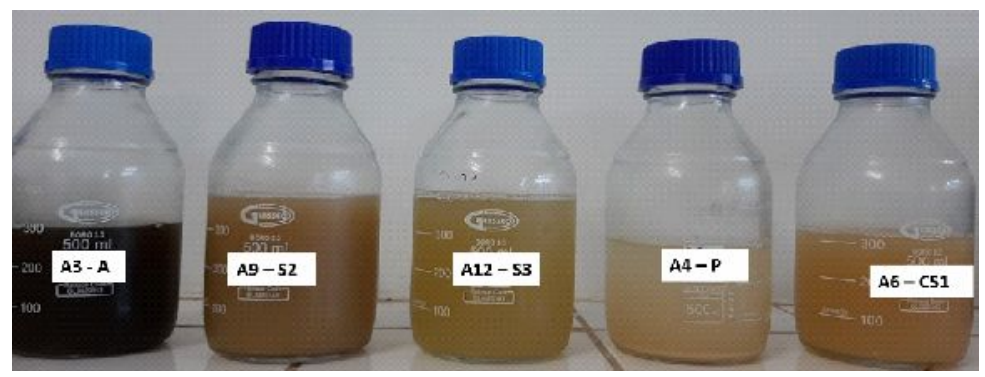

Fonte: os autores (2020) 
A análise do pH mostrou uma variação de 3.0 a 8.5 (Quadro 1), porém apresentando um perfil de acidificação em $91,6 \%$ das amostras. A diferença mais significativa foi entre as amostras com multiplicados de Saccharopolyspora spinosa, provenientes de 2 produtos diferentes e fermentados empregando diferentes meios de cultura. Assim, considerando as amostras A4 - P e A6 - CS1, multiplicados em mesmo meio de cultura (porém diferentes fontes de inóculos) observamos $\mathrm{pH}$ variando de $4.0 \mathrm{a}$ 8.5, respectivamente. Quando a comparação é em função de diferentes meios de cultura (porém, mesma fonte de inóculo) verificamos variação de 3.0 a 8.5 , para as amostras A10 - CS2 e A6 - CS1, respectivamente. Estes dados mostram grande variação dentro do sistema de fermentação, o que pode influenciar diretamente na multiplicação do microrganismo alvo e/ou dos metabólitos desejados, como por exemplo as espinosinas A e D produzidas por S. spinosa (GUOJUN et al., 2016; LU et al., 2017).

No Quadro 2 são apresentados os dados referentes a quantificação bacteriana total, coliformes totais, termotolerantes e Salmonella sp. É possível verificar que para a quantificação total, todas as amostras apresentam boa taxa populacional variando de $9 \times 10^{7}$ a $1,6 \times 10^{11}$ UFC $\mathrm{mL}^{-1}$. Ao analisar as amostras provenientes da multiplicação de Bacillus subtilis QST 713 (A8 - S1, A9 - S2 e A12 - S3), verifica-se diferença na taxa de multiplicação. Quando as bactérias são multiplicadas utilizando diferentes meios de cultura e sob as mesmas condições são esperadas diferenças nas taxas de multiplicação (A8 - S1 e A9 - S2). Já, quando multiplicadas sob as mesmas condições (recomendações) incluindo mesmo meio de cultura é esperada maior proximidade na multiplicação, caso que não acontece entre as amostras A9 - S2 e A12 - S3. Este ponto, revela que diferente de um sistema industrial, já padronizado e controlado, a multiplicação on farm necessita de melhor padronização para estabilidade da multiplicação.

Para as amostras A6 - CS1, A10 - CS2 e A4 - P (S. spinosa) verificou-se maior variação na multiplicação de bactérias totais, $3,9 \times 10^{8}, 3,1 \times 10^{10}$ e $1,6 \times 10^{11}$ UFC mL $\mathrm{mL}^{-1}$, respectivamente, revelando novamente influência do meio de cultura e falta de padronização no sistema de multiplicação. A falta de informações quanto a composição nutricional dos meios de cultura torna inviável uma discussão mais aprofundada sobre a possível variação da taxa populacional encontrada.

QUADRO 2. Quantificação de heterotróficos mesófilos totais, coliformes totais e termotolerantes e determinação da presença de Salmonella das amostras analisadas a partir da multiplicação on farm.

\begin{tabular}{|l|c|c|c|c|}
\hline Amostras & $\begin{array}{c}\text { Quantificação } \\
\text { de Bactérias } \\
\text { Heterotróficas } \\
\text { Totais (UFC } \\
\left.\mathrm{mL}^{-1}\right)\end{array}$ & $\begin{array}{c}\text { Coliformes } \\
\text { Totais } \\
(\mathrm{NMP} / \mathrm{mL})\end{array}$ & $\begin{array}{c}\text { Coliformes } \\
\text { Termotolerantes } \\
\text { (NMP/mL) }\end{array}$ & $\begin{array}{c}\text { Salmonella } \\
- \text { Shigella }\end{array}$ \\
\hline $\begin{array}{l}4,9 \times 10^{10} \\
\text { Amyloliquefaciens D-747) }\end{array}$ & $>1.100$ & 210 & Ausente \\
\hline $\begin{array}{l}\text { A2 - G (Chromobacterium } \\
\text { subtsugae) }\end{array}$ & $7,1 \times 10^{10}$ & $>1.100$ & 1.100 & Presente \\
\hline $\begin{array}{l}\text { A3 - A (Azospirillum } \\
\text { brasilense) }\end{array}$ & $5,5 \times 10^{10}$ & $>1.100$ & 21 & Presente \\
\hline
\end{tabular}




\begin{tabular}{|l|c|c|c|c|}
\hline $\begin{array}{l}\text { A4 - P (Saccharopolyspora } \\
\text { spinosa) }\end{array}$ & $1,6 \times 10^{11}$ & $>1.100$ & 93 & Presente \\
\hline $\begin{array}{l}\text { A5-B (Bacillus thuringiensis } \\
\text { var. kurstaki HD-1) }\end{array}$ & $2,4 \times 10^{11}$ & $>1.100$ & 7,4 & Presente \\
\hline $\begin{array}{l}\text { A6-CS1 (Saccharopolyspora } \\
\text { spinosa) }\end{array}$ & $3,9 \times 10^{8}$ & $>1.100$ & 11 & Presente \\
\hline $\begin{array}{l}\text { A7-CC1 (Chromobacterium } \\
\text { sp.) }\end{array}$ & $9 \times 10^{7}$ & $>1.100$ & 20 & Presente \\
\hline $\begin{array}{l}\text { A8-S1 (Bacillus subtilis QST } \\
713)\end{array}$ & $4,2 \times 10^{9}$ & $>1.100$ & $<3,0$ & Presente \\
\hline $\begin{array}{l}\text { A9-S2 (Bacillus subtilis QST } \\
713)\end{array}$ & $2,2 \times 10^{10}$ & $>1.100$ & 210 & Presente \\
\hline $\begin{array}{l}\text { A10-CS2 } \\
\text { (Saccharopolyspora spinosa) }\end{array}$ & $3,1 \times 10^{10}$ & $<3,0$ & $<3,0$ & Ausente \\
\hline $\begin{array}{l}\text { A11-CC2 (Chromobacterium } \\
\text { sp.) }\end{array}$ & $1,3 \times 10^{9}$ & $<3,0$ & $<3,0$ & Ausente \\
\hline $\begin{array}{l}\text { A12-S3 (Bacillus subtilis } \\
\text { QST 713) }\end{array}$ & $4,8 \times 10^{9}$ & $>1.100$ & $>1.100$ & Presente \\
\hline
\end{tabular}

Ao analisar as bactérias isoladas, em meio TSA, de cada amostra dos multiplicados, foram identificadas colônias com diferenças morfológicas variando de 1 a 7 morfotipos (Figura 3 A). Do total de colônias morfologicamente distintas foram recuperadas 50 isolados (Figura $3 \mathrm{~B}$ ) que foram analisados microscopicamente através da coloração de Gram. Os resultados mostraram que 62\% são Gram-positivas, 32\% Gram-negativas e 6\% identificadas como leveduras (Figura $3 \mathrm{C}$ ).

FIGURA 3. Caracterização macroscópica e microscópica de diferentes isolados provenientes de 12 amostras de multiplicados on farm. A. Diferentes morfotipos de colônias crescidas em meio TSA. B. Isolamento e purificação de colônias morfologicamente distintas. C. Caracterização microscópica a partir da coloração de Gram.

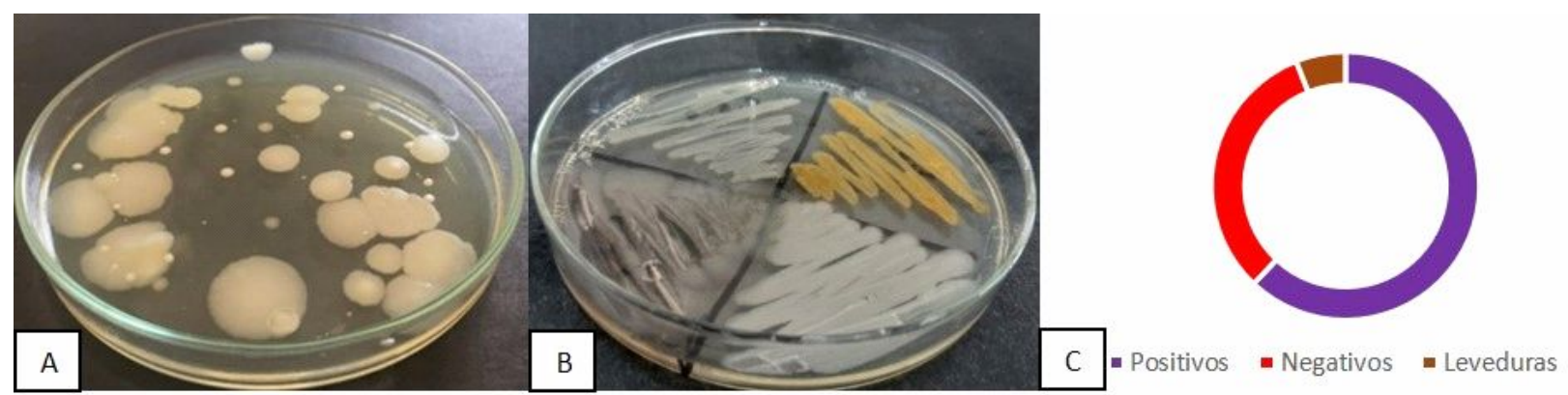

Fonte: os autores (2020)

Estes resultados apresentam informações importantes. Bactérias da espécie Chromobacterium subtsugae supostamente presentes nas amostras A2 - G, A7 - CC1 e A11 - CC2, é uma bactéria Gram-negativa que em meio de cultura Tryptona Soy Agar (TSA) cresce produzindo um pigmento, característico da maioria das espécies do gênero, chamado de violaceina, o qual confere a tonalidade violeta para as colônias ENCICLOPÉDIA BIOSFERA, Centro Científico Conhecer - Jandaia-GO, v.17 n.34; p. 436 
(BLACKBURN et al., 2016; WENFA, 2017). Em nenhuma das 3 amostras analisadas foram detectadas bactérias com estas características. Martin et al. (2007) definem que as condições ótimas de crescimento da espécie C.subtsugae PRAA4-1 são $25^{\circ} \mathrm{C}$ e pH 6.5 a 8.0, em todas as amostras analisadas o pH não atingiu o mínimo considerado. Os mesmos autores detectaram pouco crescimento da cepa nas temperaturas $10{ }^{\circ} \mathrm{C}$ e 40 ${ }^{\circ} \mathrm{C}$ e em $\mathrm{pH}$ de 5.0 e 9.0 .

Assim como para C. subtsugae PRAA4-1, as amostras contendo como base de inóculo a $S$. spinosa, não foram encontradas nenhuma bactéria com as características macro e microscópicas padrão para a espécie (DHAKAL et al., 2017). Para a amostra A4 - P, foram diferenciadas apenas dois morfotipos de colônias, e após análise microscópica foram identificadas uma bactéria Gram-negativa e uma espécie de levedura. Estes resultados sugerem que, embora tenha havido multiplicação microbiana nos reatores, para as espécies $C$. subtsugae e $S$. spinosa, $100 \%$ das bactérias isoladas, para estas amostras, foram consideradas contaminantes e não relacionadas com a bactéria alvo da multiplicação.

Ao analisar a presença e quantificação do grupo dos coliformes totais, apenas as amostras A10 - CS2 e A11 - CC2 foram negativas com contagens abaixo de 3,0 NMP $\mathrm{mL}^{-1}$. As demais amostras além de serem positivas apresentaram elevado número de bactéria do grupo dos coliformes totais. De acordo com Silva et al., (2010), neste grupo são enquadradas mais de 20 espécies de enterobactérias. As quais podem ser originárias do trato gastrintestinal de humanos e de outros animais de sangue quente (Escherichia coli), como também bactérias não entéricas (espécies de Citrobacter, Enterobacter, Klebsiella e Serratia, dentre outras). Assim, a presença e número elevado de coliformes totais é um indicativo das condições higiênicas insatisfatórias durante o processo de multiplicação, ou ainda pode revelar a possibilidade de matéria-prima de má qualidade (CONTE et al., 2004; SANTOS; CARVALHO 2017).

Já para as análises de coliformes termotolerantes houve variação de $<3.0$ a $>1.100 \mathrm{NMP} \mathrm{mL}^{-1}$ totalizando $75 \%$ de amostras positivas, sendo as maiores quantidades encontradas nas amostras A2 - G e A12 - S3. Os microrganismos deste subgrupo, dos coliformes totais, são comumente chamados de coliformes fecais. Atualmente sabe-se que além das enterobactérias originárias do trato gastrintestinal $(E$. coli), o grupo inclui membros de origem não fecal (várias cepas de Klebsiella pneumoniae, Pantoea agglomerans, Enterobacter aerogenes, Enterobacter cloacae e Citrobacter freundii). De acordo com Vasco (2010), os coliformes termotolerantes não são considerados patogênicos, mas podem atuar como indicadores da existência de patógenos verdadeiros. O principal representante do grupo termotolerante e o indicador mais específico de contaminação fecal e de eventual presença de organismos patogênicos é a $E$. coli. Determinadas cepas de $E$. coli, ao serem ingeridas pelo homem, podem resultar em sintomas desagradáveis, brandos ou agressivos (CRUZ et al., 2006).

Dentre os agentes causadores das doenças transmitidas por alimentos (DTA) cepas patogênicas de $E$. coli figuram entre os principais agentes (24\%), quando analisados os 6.903 surtos de DTA ocorridos no Brasil no período de 2009 a 2018 (BRASIL, 2019). Para o ministério da saúde, uma DTA é uma síndrome geralmente constituída de anorexia, náuseas, vômitos, e/ou diarreia, acompanhada ou não de febre relacionada a ingestão de alimentos ou água contaminados, podendo ainda haver 
afecções em diferentes órgãos como rins, fígado, sistema nervoso central, dentre outros (BRASIL, 2019). O quadro clínico é variável de acordo com o agente etiológico. Surtos de DTA são considerados eventos de saúde pública que podem representar ameaça à saúde pública, devendo, desta forma haver notificação compulsória imediata.

Os casos de surtos de DTA notificados apontados no período acima, mostram que o segundo agente etiológico mais importante são as cepas de Salmonella spp., as quais representam $11,2 \%$ dos casos. Os resultados encontrados neste trabalho indicam presença provável de Salmonella em $75 \%$ das amostras analisadas (quadro 2, figura 4). O que representa um número elevado e, de acordo com ANVISA (2001), a presença de Salmonella em amostras de alimentos torna o produto impróprio para o consumo. Análises mais detalhadas devem ser realizadas, como testes bioquímicos e sorológicos para determinação da espécie (BRASIL, 2011).

Segundo Melo et al., (2018), as infecções causadas pelas bactérias deste gênero são consideradas as mais importantes causas de DTA. Os sintomas causados pela ingestão de alimentos ou água contaminados por Salmonella spp. surgem entre 12 a 72 horas após ingestão e incluem febre, dor abdominal, diarreia, náusea e vômito, podendo durar por até 7 dias (MORROW; FUNK, 2001). Porém, sorovares mais virulentos como $S$. thyphi podem estender a infecção por até oito semanas, causando septicemia e levando à morte (BRASIL, 2011).

FIGURA 4. Determinação da presença de Salmonella sp. nas diferentes amostras de multiplicados on farm. As bactérias foram repicadas em meio Agar SalmonellaShigella, o qual apresenta elevada seletividade para Salmonella spp. Para o diagnóstico foi seguido determinação da ANVISA (2011), onde: colônias incolores com centro negro - suspeita de Salmonella spp., colônia incolor - suspeita de Shigella spp. e colônias cor de rosa ou vermelho - suspeita de Escherichia coli ou Klebsiella spp.

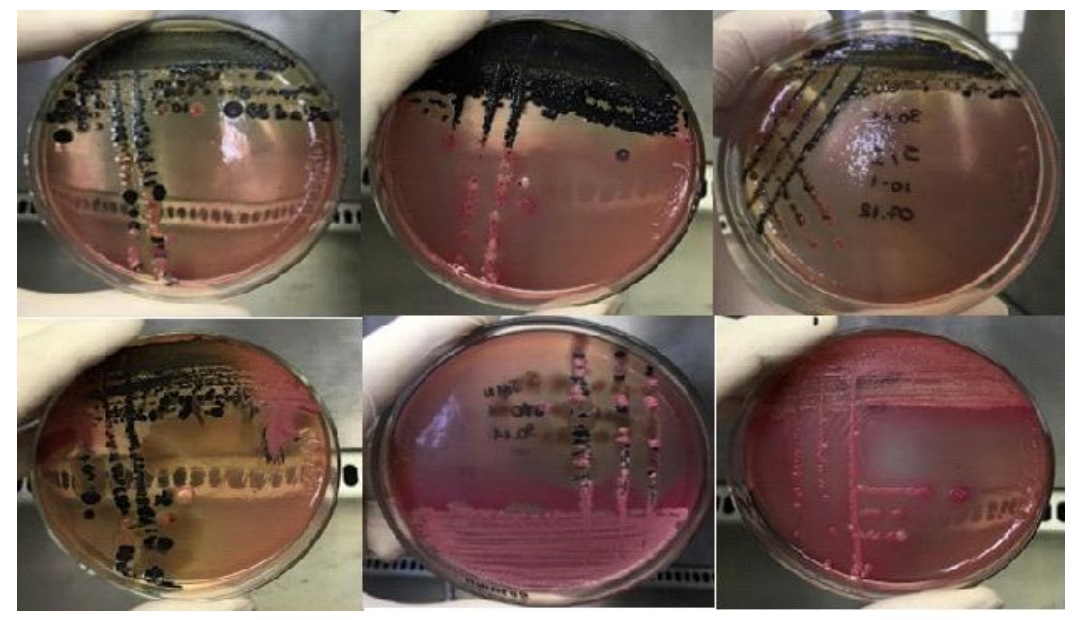

Fonte: os autores (2020)

A partir dos dados apresentados é possível levantar três principais pontos:

- O produto multiplicado, com a presença confirmada de diferentes contaminantes, apresenta eficiência do ponto de vista agronômico? 
Embora este não tenha sido o objetivo do presente trabalho, é fundamental que este questionamento possa ser considerado e discutido. A premissa da utilização da multiplicação on farm é possibilitar ao produtor produzir seu próprio insumo biológico com ação para o estímulo do crescimento e nutrição vegetal ou aqueles com função de biopesticida, objetivando reduzir custos de produção. Ao multiplicar microrganismos que não são os alvos do processo (amostras de Chromobacterium subtsugae e Saccharopolyspora spinosa), o produtor poderá estar aplicando microrganismos que não tenham nenhuma ação desejada ou multiplicando algum microrganismo que possa ser fitopatogênico. Com isso, tornando o que seria uma redução de custos em um problema que pode acarretar sérios prejuízos. Este fato pode acarretar questionamentos quanto a qualidade, já comprovada, dos produtos biológicos registrados e liberados para uso, impactando negativamente o segmento e afetando a credibilidade da tecnologia.

- os contaminantes multiplicados representam riscos para a saúde dos manipuladores e consumidores?

Este ponto merece uma análise criteriosa. Os dados disponibilizados pelo Ministério da Saúde apontam que 122.187 pessoas no Brasil ficaram doentes em função de doenças transmitidas por alimentos. Destas 16.817 foram hospitalizadas e 99 vieram a óbito. Ao permitir e favorecer a multiplicação de microrganismos como Escherichia coli e Salmonella spp. pode-se estar abrindo uma porta para o desenvolvimento de DTA aos manipuladores durante o processo de multiplicação (visto que os mesmos, na grande maioria dos casos, não utilizam equipamentos de proteção individual) e aos consumidores tanto do mercado interno quanto do produto de exportação. Valicente et al., (2018) analisando multiplicados de Bacillus thuringiensis de três propriedades rurais em Mato Grosso verificou que todas as amostras estavam contaminadas por diferentes espécies de bactérias. A conclusão do estudo foi que os produtos se mostravam inadequados para uso como biopesticida e apresentavam riscos de contaminação para humanos e animais. Assim, a contaminação em frutos, para consumo interno e para exportação, que causem alguma DTA aos consumidores, podem representar sérios prejuízos do ponto de vista econômico e de saúde pública para o Vale do São Francisco.

- é possível realizar a multiplicação on farm de forma segura e eficiente?

O fato mais importante para ser considerado é que um produto on farm nunca terá o nível de qualidade e tecnologia que um produto comercial produzido industrialmente. É preciso considerar também se vale a pena para o produtor incorporar a produção de microrganismos, da forma adequada, às atividades produtivas da propriedade. Se sim, obrigatoriamente ele deverá ter assistência técnica qualificada para desenvolvimento de todo o processo, como escolha apropriada do sistema, do meio de cultura, dos protocolos de multiplicação, considerando as especificidades de cada espécie microbiana alvo, além, obviamente, de contar com um rígido controle de qualidade. Se forem seguidas as boas práticas de produção, atrelado a um bom acompanhamento técnico, é possível desenvolver a produção on farm de forma segura e eficiente.

Os dados apresentados neste trabalho representam as primeiras informações sobre a multiplicação on farm no Vale do São Francisco. Embora os sistemas utilizados 
pelos produtores tenham a capacidade de multiplicação de microrganismos, a forma (manipulação) como é feita atualmente não representa uma tecnologia que trará garantias quanto a eficácia do produto multiplicado nem quanto a segurança alimentar dos consumidores. É imprescindível que sejam aplicados criteriosos protocolos para todo o sistema de produção da multiplicação, sendo fundamental a realização de controle de qualidade do produto final, bem como análises rotineiras dos frutos que recebem aplicações, além de testes de eficiência do produto. Como recomendação é necessário ainda, realizar análises de qualidade microbiológica da água, dos meios de cultura utilizados e do produto fonte de inóculo adquirido. Este último para garantir a fonte adequada de inóculo alvo. Verificamos também ao longo do desenvolvimento deste trabalho que é necessário qualificação teórica e prática sobre aspectos básicos relacionados à fisiologia dos microrganismos alvo da multiplicação, bem como, boas práticas de produção, para os manipuladores, para os responsáveis técnicos pelas propriedades, bem como para os representantes que comercializam algumas fontes de inóculo e os meios de cultura utilizados.

\section{CONCLUSÃO}

Todas as amostras multiplicadas on farm apresentaram contaminação por diferentes espécies de bactérias e leveduras. Nenhuma amostra multiplicada, indicada como contendo $S$. spinosa e $C$. subtsugae, apresentou estas bactérias. A maioria das amostras analisadas apresentou contaminação por coliformes totais, termotolerantes e presença provável de Salmonella spp. Testes com maior abrangência e maior detalhamento precisam ser realizados para traçar um panorama da multiplicação on farm no Vale do São Francisco bem como identificar as principais espécies contaminantes presentes nas amostras.

\section{REFERÊNCIAS}

ADESEMOYE, T.O. Introduction to biological products for crop production and protection. NExtension. University of Nebraska Lincoln. 2017. Disponível em:< http://extensionpublications.unl.edu/assets/pdf/ec3019.pdf<.

ANVISA _ Agência Nacional de Vigilância Sanitária. Resolução RDC nº 12, de 02 de janeiro de 2001. Disponível em:< http://portal.anvisa.gov.br/documents/33916/0/Resolu\%C3\%A7\%C3\%A3o+RDC+n\%C2 $\% B A+12 \% 2 C+d e+02+d e+j a n e i r o+d e+2001 / 0 f a 7518 b-92 f f-4616-85 e 9-$ bf48a6a82b48?version $=1.0>$

BLACKBURN, M. B.; SPARKS, M.E.; GUNDERSEN-RINDAL, D.E. The genome of the insectidal Chromobacterium subtsugae PRAA4-1 and its comparison with that of Chromobacterium violaceum ATCC 12472. Genomics Data. 10:1-3, 2016. Disponível em:< https://www.sciencedirect.com/science/article/pii/S2213596016301106>. https://doi.org/10.1016/j.gdata.2016.08.013

BORSARI, A.P.; CLAUDINO, M. Biodefensivos: mercado e percepção do produtor brasileiro. Agroanalysis. $\quad$ ABCBio. 2018. Disponível em:< https://www.abcbio.org.br/informativos/publicacoes/> 
BRASIL. 2002. Decreto no 4.074, de 4 de Janeiro de 2002. Disponível em:< http://www.planalto.gov.br/ccivil_03/decreto/2002/D4074.htm\#anexoii.24>

BRASIL. Ministério da Saúde. 2011. Manual técnico de diagnóstico laboratorial da Salmonella spp. $\quad$ 1.ed. $\quad$ Brasília. Disponível em:< http://bvsms.saude.gov.br/bvs/publicacoes/manual_tecnico_diagnostico_laboratorial_sal monella_spp.pdf>

BRASIL. Ministério de Agricultura. 2012. Manual de procedimentos para registro de agrotóxico. Ministério da Agricultura Pecuária e Abastecimento, 1:68. Disponível em:< http://www.agricultura.gov.br/assuntos/insumos-agropecuarios/insumos-

agricolas/agrotoxicos/arquivos/manual-de-procedimentos-para-registro-de-

agrotoxicos.pdf>

BRASIL. Ministério da Saúde. Surtos de doenças transmitidas por alimentos no Brasil. 2019. Disponível em:< http://www.saude.gov.br/saude-de-a-z/doencastransmitidas-por-alimentos>

CONTE, V. D.; COLOMBO, M.; ZANROSSO, A.V.; SALVADOR, M. Qualidade microbiológica de águas tratadas e não tratadas na região nordeste do Rio Grande do Sul. Infarma, v. 16, n. 11-12, p. 83-84, 2004. Disponível em:< https://www.cff.org.br/sistemas/geral/revista/pdf/77/i02-qualidademicro.pdf>

CRUZ, A.G.; CENCI, S.A.; MAIA, M.C.A. Pré-requisitos para implementação do sistema APPCC em uma linha de alface minimamente processada. Ciência e Tecnologia de Alimentos, v. 26, n. 1, p.104-109, 2006. Disponível em:< https://www.scielo.br/scielo.php?script=sci_arttext\&pid=S0101-20612006000100018 > . http://dx.doi.org/10.1590/S0101-20612006000100018

DHAKAL, D.; POKHREL, A.R.; JHA, A.K.; THUAN, N.H.; SOHNG, J.K. Saccharopolyspora species: Laboratory maintenance and enhanced production of secondary metabolites. Current Protocols in Microbiology. 44:10H.1.1-10H.1.13, 2017.

Disponível

em:<

https://currentprotocols.onlinelibrary.wiley.com/doi/abs/10.1002/cpmc.21 >. doi:

10.1002/cpmc.21

FDA_Food and Drug Administration. Disponível em:<https://www.fda.gov/>

GUOJUN, Y.; YUPING, H.; YAN, J.; KAICHUN, L.; XIA, H. A new medium for improving Spinosad production by Saccharopolyspora spinosa. Jundishapur Journal of Microbiology, v. $\quad 9, \quad 6$ e16765. 2016. Disponível em:< https://www.ncbi.nlm.nih.gov/pmc/articles/PMC5013548/\#: :text=In\%20the\%20present $\% 20$ study\%2C\%20a,verification\%20by\%20several\%20different\%20strains>. doi: $10.5812 / j j m .16765$

JAGANI, H.; HEBBAR, K.; GANG, S.S.; RAJ, P.V.; CHANDRASHEKHAR, R.; RAO, J.V. 
An overview of fermenter and the design considerations to enhance its productivity. Pharmacologyonline, v.1, p, 261-301, 2010. Disponível em:< https://pharmacologyonline.silae.it/files/newsletter/2010/vol1/27.lagati.pdf >

LU, C.; YIN, J.; ZHAO, F.; LI, F.; LU, W. Metabolomics analysis of the effect of dissolved oxygen on Spinosad production by Saccharopolyspora spinosa. Antonie van Leeuwenhoek, v.110, n.5, p. 677-685, 2017. Disponível em:< https://pubmed.ncbi.nlm.nih.gov/28154945/>.DOI: 10.1007/s10482-017-0835-5

MARTIN, P.A.W.; GUNDERSEN-RINDAL, D.; BLACKBURN, M.; BUYER, J. 2007. Chromobacterium subtsugae sp. nov., a betaproteobacterium toxic to Colorado potato beetle and other insect pests. International Journal of Systematic and Evolutionary Microbiology, v. 57, p.993-999, 2007. Disponível em:< https://www.microbiologyresearch.org/content/journal/ijsem/10.1099/ijs.0.64611-0>. https://doi.org/10.1099/ijs.0.64611-0.

MELO, S.E.; AMORIN, W.R.; PINHEIRO, R.E.E.; CORRÊA, P.G.N.; CARVALHO, S.M.R.; et al. Doenças transmitidas por alimentos e principais agentes bacterianos envolvidos em surtos no Brasil: revisão. Pubvet, v.12, n.10, p.1-9, 2018. Disponível em:< https://www.pubvet.com.br/artigo/5232/doenccedilas-transmitidas-por-alimentos-eprincipais-agentes-bacterianos-envolvidos-em-surtos-no-brasil>.

https://doi.org/10.31533/pubvet.v12n10a191.1-9

MORROW, W.; FUNK, J. Salmonella as a foodborne pathogen in pork. Animal Science Facts, v. 01, n. 816, p.1-5, 2001. Disponível em:< http://www.adiveter.com/ftp_public/articulo395.pdf>

SANTOS, R. B.; CARVALHO, L.R. Qualidade microbiológica de saladas de frutas comercializadas no município de Ilhéus. Rebracisa, v.1, n.1, p.1-13, 2017. Disponível em:< https://periodicos.uesc.br/index.php/rebracisa/article/view/1474>

SCHMIDELL, W.; LIMA, U.A.; AQUARONE, E.; BORZANI, W. Biotecnologia Industrial. Vol.2. Engenharia Bioquímica. São Paulo: Blucher. 2001.

SILVA, N. Manual de Métodos de análise microbiológica de alimentos e água. São Paulo: Varela. 2010

VALICENTE, F.H.; LANA, U.G.P.; PEREIRA, A.C.P.; MARTINS, J.L.A.; TAVARES, A.N.G. Riscos à produção de biopesticida à base de Bacillus thuringiensis. Circular Técnica 239. Embrapa Milho e Sorgo, Sete Lagoas, MG. 2018. Disponível em:< https://ainfo.cnptia.embrapa.br/digital/bitstream/item/179581/1/circ-239.pdf>

VASCO, A.N.; MELLO JÚNIOR, A.V.; SANTOS, A.C.A.S.; RIBEIRO, D.O.; TAVARES, E.D.; NOGUEIRA, L.C. Qualidade da água que entra no estuário do rio Vaza Barris pelo principal fluxo de contribuição de água doce. Scientia Plena, v.6, n.9, p.107-112, 2010. Disponível em:< https://www.scientiaplena.org.br/sp/article/view/96/57> 
WENFA, N. Growth of Chromobacterium violaceum on R2A and Tryptic Soy Agar. Journal contribution. $2017 . \quad$ Disponível em:< https://figshare.com/articles/Growth_of_Chromobacterium_violaceum_on_R2A_and_Try ptic_Soy_Agar/5525296/1>. https://doi.org/10.6084/M9.FIGSHARE.5525296.V1

ZHANG, W.; WEI, L.; LIN, G.; XIN, H.; LV, Z.; QIAN, H.; SHI, H. Evaluation of the Antibacterial Material Production in the Fermentation of Bacillus amyloliquefaciens- 9 from Whitespotted Bamboo Shark (Chiloscyllium plagiosum). Marine drugs, v.18, n.119, p.1-15, 2020.2 Disponível Disponível em:< https://www.ncbi.nlm.nih.gov/pmc/articles/PMC7073760/>. doi:10.3390/md18020119 